\title{
Moderate Hyperventilation during Intravenous Anesthesia Increases Net Cerebral Lactate Efflux
}

\author{
Frank Grüne, M.D., Stephan Kazmaier, M.D., Ph.D., Hans Sonntag, M.D., Ph.D., \\ Robert Jan Stolker, M.D., Ph.D., Andreas Weyland, M.D., Ph.D.
}

\section{ABSTRACT}

Background: Hyperventilation is known to decrease cerebral blood flow (CBF) and to impair cerebral metabolism, but the threshold in patients undergoing intravenous anesthesia is unknown. The authors hypothesized that reduced CBF associated with moderate hyperventilation might impair cerebral aerobic metabolism in patients undergoing intravenous anesthesia.

Methods: Thirty male patients scheduled for coronary surgery were included in a prospective, controlled crossover trial. Measurements were performed under fentanyl-midazolam anesthesia in a randomized sequence aiming at partial pressures of carbon dioxide of 30 and $50 \mathrm{mmHg}$. Endpoints were CBF, blood flow velocity in the middle cerebral artery, and cerebral metabolic rates for oxygen, glucose, and lactate. Global CBF was measured using a modified Kety-Schmidt technique with argon as inert gas tracer. CBF velocity of the middle cerebral artery was recorded by transcranial Doppler sonography. Data were presented as mean (SD). Two-sided paired $t$ tests and one-way ANOVA for repeated measures were used for statistical analysis.

Results: Moderate hyperventilation significantly decreased CBF by $60 \%$, blood flow velocity by $41 \%$, cerebral oxygen delivery by $58 \%$, and partial pressure of oxygen of the jugular venous bulb by $45 \%$. Cerebral metabolic rates for oxygen and glucose remained unchanged; however, net cerebral lactate efflux significantly increased from $-0.38(2.18)$ to $-2.41(2.43) \mu \mathrm{mol}^{-1}$ $100 \mathrm{~g}^{-1}$.

Conclusions: Moderate hyperventilation, when compared with moderate hypoventilation, in patients with cardiovascular disease undergoing intravenous anesthesia increased net cerebral lactate efflux and markedly reduced CBF and partial pressure of oxygen of the jugular venous bulb, suggesting partial impairment of cerebral aerobic metabolism at clinically relevant levels of hypocapnia. (ANesthesiology 2014; 120:335-42)

$\mathbf{H}$ YPOCAPNIA induced by hyperventilation and associated alkalosis have a wide range of physiological effects, including increased cerebrovascular resistance (CVR), decreased cerebral blood flow (CBF), cerebral oxygen delivery $\left(\mathrm{cDO}_{2}\right)$, and cerebral metabolism. ${ }^{1}$ Despite routine end-tidal carbon dioxide monitoring, periods of inadvertent hyperventilation occur frequently during mechanical ventilation under general anesthesia, which may be associated with unfavorable side effects such as cognitive dysfunction and increased length of hospital stay. ${ }^{2}$

Patients with Alzheimer disease are predisposed to postoperative cognitive dysfunction. This group of patients has an increased vasoconstrictive response to hypocapnia and concomitantly a greater increase in oxygen extraction fraction $(\mathrm{OEF})$ than control patients. ${ }^{3}$ In patients with traumatic injury, vascular disorders, or meningitis, hyperventilation is associated with an impaired aerobic cerebral metabolism, reflected by an increase in net cerebral lactate efflux (cerebral metabolic rate [CMR] of lactate [CMRL] $).{ }^{4-8}$
What We Already Know about This Topic

- Hyperventilation decreases cerebral blood flow

- The threshold at which this reduction impairs cerebral metabolism in patients under intravenous anesthesia is unknown

\section{What This Article Tells Us That Is New}

- In 30 patients scheduled for coronary surgery with fentany or midazolam anesthesia, mild hyperventilation $\left(\mathrm{PacO}_{2}\right.$, $30 \mathrm{mmHg}$ ) reduced cerebral blood flow by $60 \%$, did not alter cerebral metabolic rate for oxygen or glucose, but increased net cerebral lactate efflux, consistent with partial impairment of cerebral aerobic metabolism

However, until now there are only few studies describing the interrelation between hyperventilation and CMRL in animals and humans without cerebral diseases, and their results have not been consistent. A recent report about moderate and profound hyperventilation in anesthetized young pigs without cerebral disorder showed a reduction

This article is dedicated in memoriam to our teacher, colleague, and friend Professor Hans Sonntag, who died in 2011. Presented at Euroanaesthesia 2012, Paris, France, June 10, 2012, Poster session 7AP1-10.

Submitted for publication July 30, 2012. Accepted for publication July 29, 2013. From the Department of Anesthesiology, Erasmus MC, Rotterdam, The Netherlands (F.G., R.J.S.); Department of Anesthesiology, Critical Care, and Emergency Medicine, University of Göttingen, Göttingen, Germany (S.K., H.S.); and Department of Anesthesiology, Critical Care, Emergency, and Pain Medicine, Klinikum Oldenburg, Oldenburg, Germany (A.W.). 
in regional $\mathrm{CBF}$ and oxygen availability, resulting in tissue hypoxia as reflected by an increase in markers of anaerobic metabolism. ${ }^{9}$ Similarly, investigations using magnetic resonance spectroscopy or the Kety-Schmidt technique in awake volunteers undergoing hyperventilation showed an increase in net cerebral lactate efflux. ${ }^{8,10,11}$

The anesthetized brain might be less vulnerable to ischemia than the nonanesthetized brain as the induction of anesthesia reduces cerebral electric activity, metabolism, and flow. ${ }^{1}$ In humans, induction of intravenous anesthesia even may reduce cerebral lactate efflux. ${ }^{12-14}$ But moderate hyperventilation during anesthesia also showed a trend to increase net cerebral lactate efflux though not reaching significance. ${ }^{13,15,16}$ The relevance of this finding, however, may be limited, because of the small number of patients, which have been included in these studies.

The interrelation between moderate variations in $\mathrm{PaCO}_{2}$, CVR, CBF, global $\mathrm{CDO}_{2}$, and cerebral metabolism in patients undergoing intravenous anesthesia is thus not fully understood.

We therefore investigated the effects of variation in arterial carbon dioxide partial pressure on cerebral hemodynamics and metabolism in 30 cardiac surgical patients undergoing intravenous anesthesia. We hypothesized that moderate hyperventilation, when compared with moderate hypoventilation, will reduce $\mathrm{CBF}$ and $\mathrm{CDO}_{2}$ to an extent which might impair cerebral aerobic metabolism.

\section{Materials and Methods}

\section{Design}

The prospective study was designed and performed in a controlled, crossover design at the University of Göttingen Medical Center aiming at changes in CBF, CBF velocity $(\mathrm{V})$, and the metabolic effects of hyper- versus hypoventilation in anesthetized patients. Each patient served as his own control. Approval was obtained from the local institutional review board (Medical Ethical Committee of the GeorgAugust-University of Göttingen, Göttingen, Niedersachsen, Germany; No. 07/09/90). Study period was 27 months (February 20, 1991 until May 10, 1993).

\section{Endpoints}

The primary endpoints of the trial were changes in CBF, blood flow velocity of the middle cerebral artery $\left(\mathrm{V}_{\mathrm{MCA}}\right), \mathrm{CDO}_{2}$, CMRL, CMR of oxygen $\left(\mathrm{CMRO}_{2}\right)$, and CMR of glucose. The secondary endpoints were changes in cerebral zero-flow pressure (ZFP), effective cerebral perfusion pressure $\left(\mathrm{CPP}_{\text {eff }}\right)$, and CVR.

\section{Screening and Inclusion of Patients}

Due to logistic reasons, we could perform only 1-2 measurements per month. Thus, standard screening procedures could not be applied in this crossover trial. Patients were eligible for inclusion if scheduled for elective coronary surgery. Exclusion criteria were being older than $80 \mathrm{yr}$ of age, female sex, patient refusal, active neurological disease, and a history of cerebrovascular disease, brain injury, or intracranial surgery. All patients were informed of the purpose of the study and provided written informed consent before being enrolled. None of the eligible patients refused inclusion of the trial. There were no dropouts during the study period.

\section{Sample Size Calculation}

The intersubject and intrasubject variability of $\mathrm{CBF}$ and cerebral lactate metabolism has been reported in earlier studies. ${ }^{10,13,15,16}$ However, there was a lack of data regarding the variance of the CMRL measurement method in anesthetized patients, which was necessary for an exact sample size calculation for this crossover trial. We expected a $50 \%$ difference of CMRL with an estimated effect size of $0.7-0.8$. For a statistical power of $0.8-0.9$, the sample size had to be between 24 and 30 patients. Therefore, we projected a sample size of 30 patients.

\section{Anesthesia Procedure}

Individual medications were continued until surgery. Anesthesia was induced by intravenous administration of $7 \mu \mathrm{g} / \mathrm{kg}$ of fentanyl, $0.2 \mathrm{mg} / \mathrm{kg}$ of midazolam, and $0.1 \mathrm{mg} / \mathrm{kg}$ of pancuronium. Anesthesia was maintained with $10 \mu \mathrm{g} \cdot \mathrm{kg}^{-1} \cdot \mathrm{h}^{-1}$ of fentanyl and $150 \mu \mathrm{g} \cdot \mathrm{kg}^{-1} \cdot \mathrm{h}^{-1}$ of midazolam. The anesthesia procedure, the details of mechanical ventilation, and the methods of insertion of catheters have been described in detail in a previous report. ${ }^{14}$

\section{Measurements}

Cerebral blood flow was measured with the use of modified Kety-Schmidt inert gas saturation technique with argon as a tracer gas. ${ }^{14,17,18}$ The wash-in period was $10 \mathrm{~min}$. Blood samples were obtained simultaneously from the arterial and jugular bulb catheters at a constant rate of $0.5 \mathrm{ml} / \mathrm{min}$ by a high-precision aspiration pump with gas-tight Hamilton glass syringes. The withdrawal rate for probes of the argon end-concentration was $5 \mathrm{ml} / 20 \mathrm{~s}$. A brain-blood partition coefficient of 1.10 was used to calculate CBF. ${ }^{19,20}$

Blood flow velocity in the proximal (M1) segment of the MCA was measured by transcranial Doppler sonography as extensively described in earlier reports. ${ }^{14,21,22}$ Because transcranial Doppler measurements of $\mathrm{V}_{\mathrm{MCA}}$ from the transtemporal window fail with above average incidence in elder female patients, we included only male patients in this study. ${ }^{23,24}$

Measurements were performed at two different $\mathrm{PaCO}_{2}$ levels, approximately 50 and $30 \mathrm{mmHg}$, in a randomized sequence before surgery. All measurements were performed during hemodynamic and respiratory steady-state conditions. The time interval between the measurements was $20 \mathrm{~min}$. Blood samples were drawn twice, at the beginning and end of each argon wash-in period, to measure hemoglobin concentration, blood gas analysis (ABL; Radiometer, Copenhagen, Denmark), and blood glucose and lactate concentrations (enzymatic tests kids; Boehringer, Mannheim, Germany). For comparisons with CBF measurements, $\mathrm{V}_{\mathrm{MCA}}$ was averaged during the 10-min period of each argon wash-in maneuver. End-expiratory concentrations of carbon 
dioxide were continuously recorded to ensure a stable $\mathrm{PaCO}_{2}$ during argon saturation.

\section{Calculations}

Cerebral ZFP was calculated at the beginning and end of each CBF measurement from two simultaneous 10-s recordings (two breathing cycles) of the $\mathrm{V}_{\mathrm{MCA}}$ envelope and arterial pressure curves. During each 10-s period, we first averaged diastolic, mean, and systolic data of arterial blood pressure (ABP) and $\mathrm{V}_{\mathrm{MCA}}$ to obtain a pressure-flow velocity plot. Cerebral ZFP was then extrapolated by linear regression analysis of the $A B P-V_{M C A}$ relationship. The ABP axis intercept of the regression line determines the ZFP. ${ }^{22,25}$ The cerebral ZFP was used as a measure of the effective downstream pressure of the cerebral circulation. Consequently, $\mathrm{CPP}_{\text {eff }}$ and CVR were calculated as $\mathrm{CPP}_{\text {eff }}=$ mean $\mathrm{ABP}-\mathrm{ZFP}$ and $\mathrm{CVR}=$ $\mathrm{CPP}_{\text {eff }} \cdot \mathrm{CBF}^{-1}$, respectively. Cerebrovascular $\mathrm{CO}_{2}$ reactivity was calculated from the slope of the linear regression line of the relationship between $\mathrm{CBF}$ and $\mathrm{PaCO}_{2}$ as well as $\mathrm{V}_{\mathrm{MCA}}$ and $\mathrm{PaCO}_{2}$. Relative $\mathrm{CO}_{2}$ reactivity was calculated as the percentage of change in $\mathrm{CBF}$ or $\mathrm{V}_{\mathrm{MCA}}$ per $\mathrm{mmHg}$ change in $\mathrm{PaCO}_{2}{ }^{26}$

$\mathrm{CMRO}_{2}, \mathrm{CMR}$ of glucose, and CMRL were calculated based on the reversed Fick principle, multiplying CBF by the difference in arterio-jugular venous content of oxygen $\left(\mathrm{AJVDO}_{2}\right)$, lactate (AJVDL), and glucose. ${ }^{8}$ By definition, positive CMR values indicate consumption or net influx, and negative values indicate production or net efflux. For AJVDL and CMRL, we thus expected negative values in case of cerebral lactate production.

The OEF was calculated as the ratio between $\mathrm{AJVDO}_{2}$ and arterial oxygen content. The lactate-oxygen index (LOI), which relates cerebral lactate production to oxygen extraction, was defined as LOI [] = AJVDL $[\mathrm{mm}] \mathrm{AJVDO}_{2}^{-1}[\mathrm{~mm}]$. The lactate-glucose index (LGI), that is, the fraction of glucose consumption that is metabolized and excreted from brain as lactate, was defined as the ratio between the arteriojugular venous content differences of lactate and glucose. For these calculations, contents of oxygen and glucose concentrations have been converted in to mm. Because one molecule of glucose is metabolized to two molecules of lactate, an LGI of, for example, -0.1 indicates, that $5 \%$ of the cerebral glucose consumption have been metabolized to lactate. ${ }^{5,8,27}$

\section{Statistical Analysis}

The results presented in tables are expressed as mean (SD) unless otherwise stated. To provide an estimate of the effect of hypocapnia and its clinical meaningfulness, we calculated mean differences (MD) and their 95\% CIs (MD; 95\% CI, lower bound, upper bound; $P$ value). ${ }^{28}$ The difference between hyperventilation and hypoventilation was calculated using $t$ tests for paired data or Welch test and nonparametric Wilcoxon signed-rank tests, if indicated. To prevent from type I error inflation, all primary endpoints were tested by one-way ANOVA for repeated measurements followed by Bonferoni multiple comparison tests. All statistical analyses were performed two-sided, and a $P$ value of less than 0.05 was considered to be significant.

Calculations were performed using SPSS 17 (IBM SPSS Statistics, Armonk, NY), and graphs were made using Prism 6.0c (GraphPad Software, La Jolla, CA).

Sample size calculation was done with G*Power 3 (University of Düsseldorf, Department of Psychology, Düsseldorf, Germany). ${ }^{29}$

\section{Results}

A total of 30 male patients were included in the study. The mean age of the patients was 56(8) yr (median, 58; range, 41-78 yr), mean height $173(6) \mathrm{cm}$, and mean body weight $77(9) \mathrm{kg}$. In one patient, CBF could not be measured during hypoventilation, because of technical problems during jugular venous blood sampling. Hemodynamic and metabolic data are presented in table 1.

Due to the controlled adjustment of mechanical ventilation, the variability of $\mathrm{PaCO}_{2}$ at both target levels was small. The blood temperature of the patients was effectively kept constant. Only one of our patients had diabetes mellitus. None of the patients showed increased levels of blood glucose.

The effects of ventilatory changes on the cerebral circulation were substantial. Hyperventilation reduced $\mathrm{CBF}$ by $60 \%$, and $\mathrm{V}_{\mathrm{MCA}}$ by $41 \%$, when compared with hypoventilation. This reduction was predominantly caused by increased CVR (MD, 0.95; 95\% CI, 0.75-1.11 mmHg $\cdot \mathrm{m}$ $\left.1^{-1} \cdot \mathrm{min}^{-1} \cdot 100 \mathrm{~g}^{-1} ; P<0.001\right)$ and decreased $\mathrm{CPP}_{\text {eff }}(-14 \%)$. The decrease in $\mathrm{CPP}_{\text {eff }}$ during hyperventilation occurred because of a significant increase in the cerebral ZFP (MD, 13; 95\% CI, 9-16 mmHg; $P<0.001$ ), which exceeded the small increase in mean arterial pressure (MD, 5; 95\% CI, $2-8 \mathrm{mmHg} ; P=0.003)$. The decrease in $\mathrm{CBF}$ and $\mathrm{cDO}_{2}$ (by 58\%) during hyperventilation was associated with a pronounced decrease in the venous jugular bulb oxygen saturation (MD, 31; 95\% CI, 34-28\%; $P<0.001)$ and venous jugular bulb partial pressure of oxygen $\left(\mathrm{PjvO}_{2}\right.$; MD, 21; 95\% CI, $19-22 \mathrm{mmHg} P<0.001$; fig. 1$)$. The $\mathrm{cDO}_{2} / \mathrm{CMRO}_{2}$ ratio changed from $4.5: 1$ to $1.8: 1$; that is, the OEF during hyperventilation markedly increased from 0.24 to 0.57 .

Mean arterial-jugular venous difference of oxygen, glucose, and lactate changed significantly during moderate hyperventilation when compared with hypoventilation (table 1). The mean cerebral efflux of lactate significantly increased, by $2.0 \mu \mathrm{mol} \cdot \mathrm{min}^{-1} \cdot 100 \mathrm{~g}^{-1}$, whereas mean $\mathrm{CMRO}_{2}$ and CMR of glucose remained constant. LOI and LGI significantly decreased, that is, became more negative.

Cerebrovascular $\mathrm{CO}_{2}$ reactivity of CBF was 2.02 (1.18) $\mathrm{ml} \cdot \mathrm{min}^{-1} \cdot 100^{-1} \cdot \mathrm{mmHg}^{-1}$, corresponding to a relative change of $2.79(0.77) \% \cdot \mathrm{mmHg}^{-1}$. The cerebrovascular $\mathrm{CO}_{2}$ reactivity of mean $\mathrm{V}_{\mathrm{MCA}}$ was $1.18(0.48) \mathrm{cm} \cdot \mathrm{s}^{-1} \cdot \mathrm{mmHg}^{-1}$, corresponding to a relative change of $2.03(0.50) \% \cdot \mathrm{mmHg}^{-1}$, 
Table 1. Hemodynamic and Metabolic Data during Moderate Changes in $\mathrm{PacO}_{2}$ in Patients without Cerebral Disease with Intravenous Anesthesia

\begin{tabular}{|c|c|c|c|c|c|}
\hline $\begin{array}{l}\text { Parameters } \\
(\mathrm{n}=30)\end{array}$ & Units & $\begin{array}{l}\text { Hyperventilation, } \\
\text { Mean (SD) }\end{array}$ & $\begin{array}{l}\text { Hypoventilation, } \\
\text { Mean (SD) }\end{array}$ & $\begin{array}{l}\text { Mean Differences } \\
(\mathrm{Cl}, 5 \% ; 95 \%)\end{array}$ & $P$ Value \\
\hline $\begin{array}{l}\mathrm{PaCO}_{2} \\
\mathrm{CBF}^{*}+\end{array}$ & $\begin{array}{c}\mathrm{mmHg} \\
\mathrm{ml} \cdot \mathrm{min}^{-1} \cdot 100 \mathrm{~g}^{-1}\end{array}$ & $\begin{array}{l}31(3) \\
27(6)\end{array}$ & $\begin{array}{l}51(3) \\
68(24)\end{array}$ & $\begin{array}{l}20(19 ; 21) \\
41(28 ; 53)\end{array}$ & $\begin{array}{l}<0.001 \\
<0.001\end{array}$ \\
\hline $\mathrm{V}_{\mathrm{MCA}} \operatorname{mean}^{*} \dagger$ & $\mathrm{cm} / \mathrm{s}$ & $34(12)$ & $58(17)$ & $24(19 ; 28)$ & $<0.001$ \\
\hline MAP & $\mathrm{mmHg}$ & $76(12)$ & $71(11)$ & $-5(-8 ;-2)$ & 0.003 \\
\hline ZFP† & $\mathrm{mmHg}$ & $24(9)$ & $11(11)$ & $-13(-16 ;-9)$ & $<0.001$ \\
\hline $\mathrm{CPP}_{\text {eff }}$ & $\mathrm{mmHg}$ & $51(11)$ & $59(14)$ & $8(4 ; 12)$ & $<0.001$ \\
\hline CVR† & $\mathrm{mmHg} \cdot \mathrm{ml}^{-1} \cdot \mathrm{min}^{-1} \cdot 100 \mathrm{~g}^{-1}$ & $1.93(0.52)$ & $0.95(0.32)$ & $-0.95(-1.11 ;-0.75)$ & $<0.001$ \\
\hline $\mathrm{Hb}$ & $\mathrm{mg} / \mathrm{dl}$ & $12.7(1.5)$ & $12.4(1.4)$ & $-0.3(-0.5 ; 1.0)$ & 0.505 \\
\hline Temp $_{\text {Blood }}$ & ${ }^{\circ} \mathrm{C}$ & $35.3(0.4)$ & $35.3(0.5)$ & $-0.06(-0.15 ; 0.03)$ & 0.166 \\
\hline $\mathrm{pH}_{\text {art }}$ & - & $7.48(0.03)$ & $7.30(0.03)$ & $-0.18(-0.19 ;-0.16)$ & $<0.001$ \\
\hline $\mathrm{SaO}_{2} \dagger$ & $\%$ & $96(1)$ & $95(2)$ & $-1.6(-2.4 ;-0.7)$ & $<0.001$ \\
\hline $\mathrm{SjvO}_{2} \dagger$ & $\%$ & $41(8)$ & $72(5)$ & $31(28 ; 34)$ & $<0.001$ \\
\hline $\mathrm{PaO}_{2}$ & $\mathrm{mmHg}$ & $121(31)$ & $109(28)$ & $-11(-23 ; 0)$ & 0.047 \\
\hline $\mathrm{PjvO}_{2} \dagger$ & $\mathrm{mmHg}$ & $30(9)$ & $46(5)$ & $16(13 ; 19)$ & $<0.001$ \\
\hline $\operatorname{AJVDO}_{2} \dagger$ & $\mathrm{mg} / \mathrm{dl}$ & $9.7(1.6)$ & $3.9(0.9)$ & $-5.8(-6.3 ;-5.3)$ & $<0.001$ \\
\hline AJVDG & $\mathrm{mg} / \mathrm{dl}$ & $11.2(2.7)$ & $5.6(2.3)$ & $-5.6(-4.4 ;-6.9)$ & $<0.001$ \\
\hline AJVDL† & $\mathrm{mM}$ & $-0.080(0.079)$ & $-0.003(0.033)$ & $0.077(0.047 ; 0.107)$ & $<0.001$ \\
\hline $\mathrm{cDO}_{2}{ }^{*} \dagger$ & $\mathrm{ml} \cdot \mathrm{min}^{-1} \cdot 100 \mathrm{~g}^{-1}$ & $4.61(0.83)$ & $11.08(4.01)$ & $6.49(4.42 ; 8.51)$ & $<0.001$ \\
\hline $\mathrm{CMRO}_{2}{ }^{*}$ & $\mathrm{ml} \cdot \mathrm{min}^{-1} \cdot 100 \mathrm{~g}^{-1}$ & $2.64(0.68)$ & $2.51(0.77)$ & $-0.14(-0.20 ; 0.48)$ & $>0.999$ \\
\hline $\mathrm{CMRG}^{*}$ & $\mathrm{mg} \cdot \mathrm{min}^{-1} \cdot 100 \mathrm{~g}^{-1}$ & $3.10(1.23)$ & 3.56 (1.49) & $0.46(1.43 ; 0.51)$ & $>0.999$ \\
\hline $\mathrm{CMRL}^{*}$ & $\mu \mathrm{mol} \cdot \mathrm{min}^{-1} \cdot 100 \mathrm{~g}^{-1}$ & $-2.41(2.43)$ & $-0.38(2.18)$ & 2.03 (0.60; 3.48) & 0.003 \\
\hline OEF & - & $0.57(0.09)$ & $0.24(0.05)$ & $-0.34(-0.36 ;-0.31)$ & $<0.001$ \\
\hline LOI & - & $-0.014(0.014)$ & $-0.004(0.016)$ & $0.011(0.004 ; 0.018)$ & $<0.001$ \\
\hline LGI & - & $-0.13(0.13)$ & $-0.03(0.15)$ & $0.11(0.04 ;-0.18)$ & 0.003 \\
\hline
\end{tabular}

The $P$ values, which refer to the difference between hyperventilation and hypoventilation, were calculated using two-sided $t$ test for paired data ( $\mathrm{n}=30$ ).

* Statistical analyses of primary endpoints were adjusted by one-way ANOVA for repeated measurements with Bonferoni multiple comparison procedure $(n=29)$. † Because the variances of some outcome variables substantially differed between hyperventilation vs. hypoventilation, these parameters were additionally examined by Welch test and nonparametric Wilcoxon signed-rank tests, which showed that the differences persist.

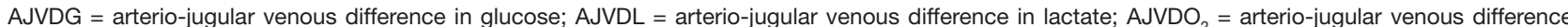
in oxygen; $\mathrm{CBF}=$ cerebral blood flow; $\mathrm{CDO}_{2}=$ cerebral oxygen delivery; $\mathrm{CMRG}=$ cerebral metabolic rate of glucose; $\mathrm{CMRL}=\mathrm{cerebral}$ metabolic rate of lactate; $\mathrm{CMRO}_{2}=$ cerebral metabolic rate of oxygen; $\mathrm{CPP}_{\text {eff }}=$ effective cerebral perfusion pressure; CVR = cerebrovascular resistance; $\mathrm{Hb}=$ hemoglobin concentration; $\mathrm{LGI}=$ lactate-glucose index; $\mathrm{LOI}=$ lactate-oxygen index; $\mathrm{MAP}=$ mean arterial pressure; $\mathrm{OEF}=\mathrm{oxygen}$ extraction fraction; $\mathrm{PaCO}{ }_{2}=$ arterial partial pressure of carbon dioxide; $\mathrm{PaO}_{2}=$ arterial partial pressure of oxygen; $\mathrm{pH}_{\text {art }}=$ negative logarithm of $\mathrm{H}^{+}$concentration (molarity) of arterial blood; $\mathrm{PjvO}_{2}=$ jugular venous partial pressure of oxygen; $\mathrm{SaO}_{2}=$ arterial blood saturation; $\mathrm{SjvO}_{2}=$ venous blood saturation of the jugular bulb; Temp $\mathrm{Blood}=$ blood temperature; $\mathrm{V}_{\mathrm{MCA}}$ mean = mean blood flow velocity of the middle cerebral artery; ZFP = zero-flow pressure.

which was significantly lower than the relative $\mathrm{CO}_{2}$ reactivity of CBF (MD, $-0.76 ; 95 \% \mathrm{CI},-0.96$ to $-0.56 ; P<0.001)$.

\section{Discussion}

We investigated the effects of variations in arterial carbon dioxide partial pressure on cerebral hemodynamics and metabolism in cardiac surgical patients undergoing fentanyl or midazolam anesthesia. Compared with hypoventilation, moderate hyperventilation was associated with a significant reduction in $\mathrm{CBF}, \mathrm{CDO}_{2}$, and $\mathrm{PjvO}_{2}$. The mean cerebral efflux of lactate significantly increased, whereas mean $\mathrm{CMRO}_{2}$ and CMR of glucose remained constant.

Hyperventilation reduces $\mathrm{PaCO}_{2}$ and decreases extracellular $\mathrm{H}^{+}$, leading to cerebral vasoconstriction and consecutively to reduced $\mathrm{CBF}$ and $\mathrm{CDO}_{2} \cdot{ }^{1} \mathrm{An}$ associated increase in net cerebral efflux of lactate at low $\mathrm{PaCO}_{2}$ levels in principle may be explained by different mechanisms:

- Dissociation of oxygen-binding curve to the left as a result of the respiratory alkalosis (Bohr effect) $)^{30-32}$
- Alkalosis induced change of redox systems of lactate/pyruvate and NADH/NAD ${ }^{+},{ }^{16,33-35}$ and

- Severe cerebral hypoperfusion with tissue hypoxia.9,36,37

Recent investigations on lactate kinetics and oxygenation using lactate isotopes demonstrate simultaneous lactate uptake and release in the brain. ${ }^{38}$ In addition to glucose and ketone bodies, lactate is also known to be an essential part of cerebral energy metabolism. Recent trials have shown that the glucose taken up by astrocytes is converted to lactate, and that the lactate released from astrocytes may be taken up by neurons and used as energy, especially in activated neurons, referred to as the astrocyteneuron lactate shuttle hypothesis. ${ }^{39}$ Thus, partial metabolic compartmentalization appears to exist between astrocytes and neurons, with astrocytes feeding the neurons with lactate generated from glycolysis upon cerebral activation. ${ }^{40}$

The magnitude of change in mean CMRL of our patients was $2.0 \mu \mathrm{mol} \cdot \mathrm{min}^{-1} \cdot 100 \mathrm{~g}^{-1}$, which was greater than expected. Previous studies have shown that absolute levels of CMRL may considerably vary depending on the group of patients and the 

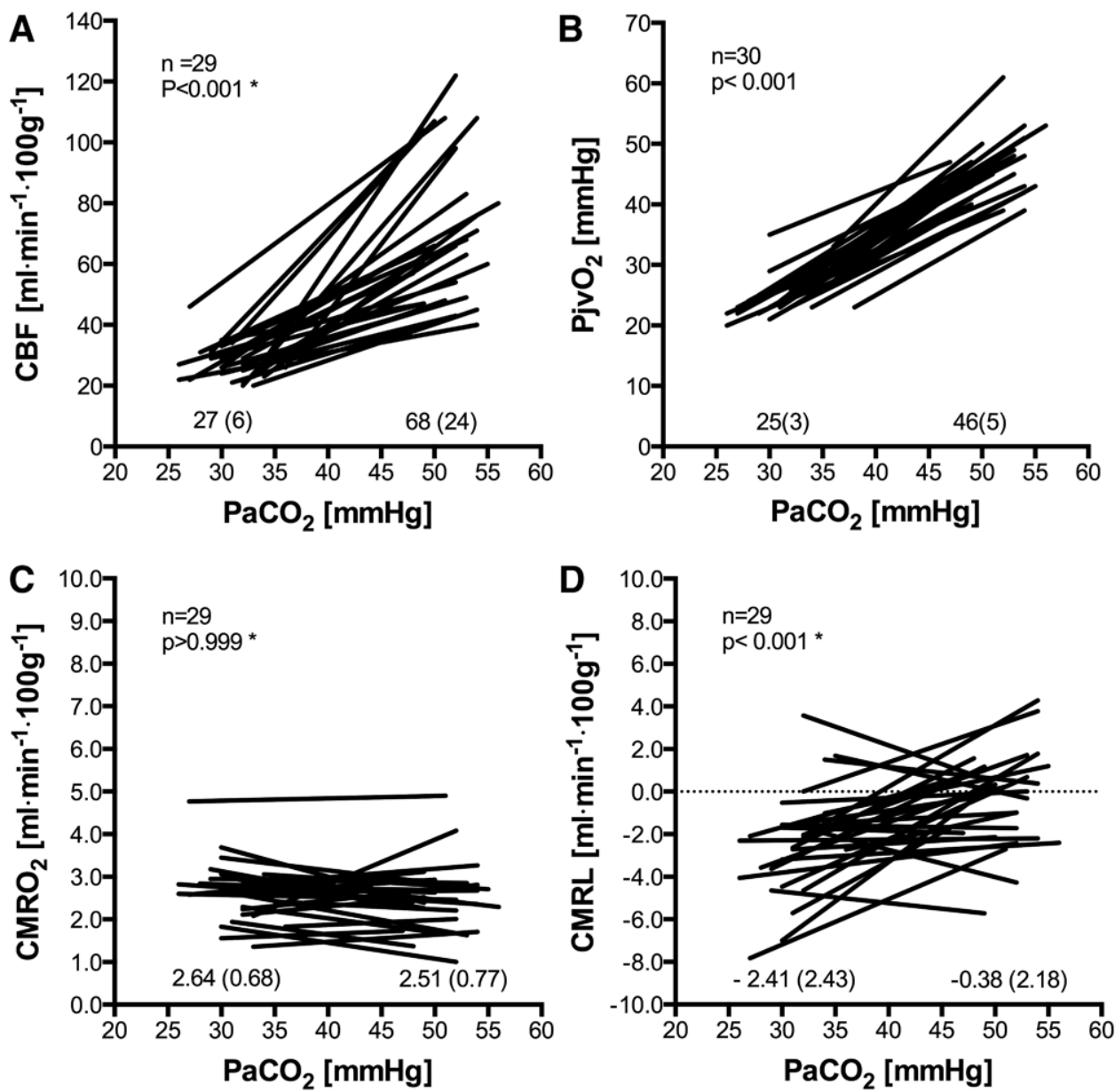

Fig. 1. $(A-D)$ Values of cerebral blood flow $(\mathrm{CBF})$, jugular venous partial pressure of oxygen $\left(\mathrm{PjvO}_{2}\right)$, cerebral metabolic rate of oxygen $\left(\mathrm{CMRO}_{2}\right)$, and lactate $(\mathrm{CMRL})$ during moderate hyperventilation compared with moderate hypoventilation. Straight lines link individual values for each subject. Data are mean (SD) for each measurement. The $P$ values, which refer to the difference between hyperventilation and hypoventilation, were calculated using two-sided $t$ tests for paired data. $P$ values of primary endpoints were adjusted by Bonferoni multiple comparisons procedure ( ${ }^{*}$ ). $\mathrm{PacO}_{2}=$ arterial partial pressure of carbon dioxide.

level of consciousness. ${ }^{14,15,41,42}$ Absolute values of net cerebral lactate efflux in our patients thus have to be interpreted with care. A slight lactate efflux at hypocapnia may not necessarily indicate tissue hypoxia. However, the increase in AJVDL and net cerebral lactate efflux associated with hypocapnia and the concomitant decrease in CBF might be suspicious for anaerobic metabolism in relatively ischemic brain regions.

It seems unlikely that the increase of net cerebral lactate efflux at low $\mathrm{PaCO}_{2}$ levels might solely be caused by alkalosisinduced enzymatic effects. There are no oxygen stores in the brain in contrast to myoglobin which stores oxygen in the muscle. Thus, the rate of oxygen delivery from the blood to brain tissue critically depends on the vessel-to-tissue oxygen partial pressure $\left(\mathrm{P}_{\mathrm{ti}} \mathrm{O}_{2}\right)$ gradient and the efficiency of oxygen transfer from the capillary bed. ${ }^{43,44} \mathrm{~A}$ definite ischemic threshold for brain tissue oxygenation has not yet been defined. Jones et al..$^{45}$ demonstrated that CBF less than 18 $\mathrm{ml} \cdot \mathrm{min}^{-1} \cdot 100 \mathrm{~g}^{-1}$ in awake monkeys results in irreversible brain tissue infarction. Michenfelder et al. ${ }^{46}$ reported critical CBF values of approximately $10-20 \mathrm{ml} \cdot \mathrm{min}^{-1} \cdot 100 \mathrm{~g}^{-1}$ in patients with ischemic changes in electroencephalography during carotid endarterectomy. In awake humans under normocapnic conditions, the $\mathrm{CDO}_{2} / \mathrm{CMRO}_{2}$ ratio is approximately 3:1 corresponding to an OEF of $0.33 .^{8,47}$ An OEF of greater than 0.4 in patients with traumatic head injury corresponded to a critically increased microdialysis lactate/pyruvate ratio which might reflect a mismatch between substrate demand and delivery on a cellular level. ${ }^{48}$ In our patients, the OEF considerably exceeded the threshold of 0.4 during hyperventilation, mainly caused by a reduction of $\mathrm{cDO}_{2}$ while $\mathrm{CMRO}_{2}$ remained unchanged.

Most investigators have considered jugular venous $\mathrm{PO}_{2}$ below $20 \mathrm{mmHg}$ and tissue $\mathrm{PO}_{2}$ values below $10 \mathrm{mmHg}$ as pathological. Clausen et al. ${ }^{9}$ showed that even moderate hyperventilation $\left(\mathrm{PaCO}_{2}=30 \mathrm{mmHg}\right.$ ) leads to a critical reduction of regional CBF below $18 \mathrm{ml} \cdot \mathrm{min}^{-1} \cdot 100 \mathrm{~g}^{-1}$ in $22 \%$ of observed pigs; the tissue oxygen pressure decreased below 10 $\mathrm{mmHg}$ in $30 \%$ of the animals undergoing moderate hyperventilation. Furthermore, recent investigations showed that the final diffusion gradient from the microcirculation to the 
mitochondria is quite small. ${ }^{49}$ Then, oxygen tension might play an essential role in mitochondrial cellular oxygen sensing and oxygen-regulated gene expression in clinical situations of low $\mathrm{CDO}_{2}{ }^{50,51}$

Although net cerebral lactate efflux during hyperventilation increased in our patients, $\mathrm{CMRO}_{2}$ did not significantly change. Similarly, several previous studies found a reduction of tissue or cerebral venous oxygen tensions during moderate hyperventilation, but no decrease in $\mathrm{CMRO}_{2}$ could be demonstrated. ${ }^{8,10,15,16,52,53}$

In contrast, other investigations could demonstrate that hyperventilation leads to a substantial decrease in $\mathrm{CMRO}_{2}{ }^{35,54}$ or tissue oxygen pressure. ${ }^{9}$ However, investigations on $\mathrm{CBF}$ and cerebral metabolism with variations of $\mathrm{PaCO}_{2}$ in anesthetized patients or volunteers without cerebral disease are scarce and also showed an unchanged $\mathrm{CMRO}_{2}$ at moderately low $\mathrm{PacO}_{2}$ levels. ${ }^{8,13,15,55}$ The Kety-Schmidt method measures only global CBF and metabolism. In case of regional hypoperfusion with increased $\mathrm{CMRO}_{2}$ in other regions of the brain, global $\mathrm{CMRO}_{2}$ may be unaffected. Only when global oxygen availability decreases below oxygen demand, $\mathrm{CMRO}_{2}$ will decrease. The results of our report demonstrate that moderate hyperventilation, when compared with hypoventilation, leads to a significant decrease in venous jugular bulb oxygen saturation, $\mathrm{PjvO}_{2}$, $\mathrm{AJVDO}_{2}, \mathrm{CBF}$, and thus $\mathrm{cDO}_{2}$. Net cerebral lactate efflux increased, which was associated with more negative LOI and LGI. Thus, our data do not indicate a severely disordered energy metabolism after a short phase of moderate hyperventilation, but it suggests that cerebral aerobic metabolism may partly be impaired. However, the clinical significance of these findings remains unclear, because in humans without cerebrovascular or traumatic brain injury detrimental effects of hyperventilation in terms of morphologic or histologic changes have not yet been demonstrated.

For the analysis of our data, different methodological aspects have to be considered.

First, the a priori sample size calculation was based on estimation of the effect size because of a lack of data regarding CMRL. A post hoc calculation, however, showed a statistical power of $97 \%(n=30, \alpha$ error probability $=0.05$; effect size of 0.73$)$.

Furthermore, the type of anesthesia may have potential influence on the results of our study. Induction of anesthesia with fentanyl and midazolam leads to a moderate but proportional reduction in $\mathrm{CBF}$ and cerebral metabolism. ${ }^{12,14,56}$ The cerebrovascular $\mathrm{CO}_{2}$ reactivity in our patients favorably compared with data in conscious patients. Although we thus have no reason to assume that intravenous anesthesia with fentanyl and midazolam per se may have affected the $\mathrm{PCO}_{2}-$ induced changes in CMRL in our patients, the results of this study cannot a priori be extrapolated to other types of anesthesia.

Similarly, the external validity of our data could be limited by the fact that our patients were suffering from coronary artery disease and concomitant asymptomatic cerebrovascular disease cannot completely be excluded despite normal cerebrovascular $\mathrm{CO}_{2}$ reactivity. Therefore, the conclusions from our study results should be limited to this patient population.

The changes in CBF induced by hyperventilation and hypoventilation are related to changes in CVR and CPP. The calculation of these variables commonly requires measurements of intracranial pressure. We used a minor invasive method to estimate cerebral ZFP and CPP eff by extrapolating pressure-flow velocity plots using recordings of $\mathrm{ABP}$ and $\mathrm{V}_{\mathrm{MCA}}$. This technique, however, is well established and may even provide a more meaningful quantification of the cerebral downstream pressure than intracranial pressure, particularly in the absence of intracranial hypertension. ${ }^{6,22,57,58}$ The finding that moderate hyperventilation leads to a small but significant reduction of $\mathrm{CPP}_{\text {eff }}$ due to a significant increase in ZFP is in accordance with previous trials investigating the effects of hyperventilation on the effective downstream pressure of the cerebral circulation. ${ }^{6,22,57,58}$

The Kety-Schmidt method has been considered a reference method for estimating global $\mathrm{CBF}^{59-61}$ In contrast to positron emission tomography or single-photon emission computed tomography, the Kety-Schmidt technique is largely independent of assumptions regarding tracer kinetics, but might slightly overestimate global CBF in case of incomplete cerebral tracer saturation. Because of the crossover design of our study, a slight systematic overestimation of $\mathrm{CBF}$ has minor importance for the interpretation of hemodynamic and metabolic changes.

In our investigation, we studied CBF and metabolism aiming at $\mathrm{PaCO}_{2}$ levels of 30 and $50 \mathrm{mmHg}$. We chose these $\mathrm{PaCO}_{2}$ levels because they roughly reflect the range of unintended variations of $\mathrm{PaCO}_{2}$ that often occur in routine clinical practice. The lack of data during normocapnia is a potential limitation of our study. Individual extrapolation of CBF at a $\mathrm{PaCO}_{2}$ of $40 \mathrm{mmHg}$ gave a mean CBF under normocapnia of $48(10) \mathrm{ml} \cdot \mathrm{min}^{-1} \cdot 100 \mathrm{~g}^{-1}$. The absolute and relative $\mathrm{CO}_{2}$ reactivity of $\mathrm{CBF}$ is in accordance with previous studies on the cerebral circulation during general anesthesia. This underlines the validity of our hemodynamic measurements. ${ }^{8,13,18,55,62}$ Interestingly, the relative cerebrovascular $\mathrm{CO}_{2}$ reactivity of CBF was significantly higher than cerebrovascular $\mathrm{CO}_{2}$ reactivity of $\mathrm{V}_{\mathrm{MCA}}$. The most probable explanation is that changes in $\mathrm{PaCO}_{2}$ do not only cause changes in vascular diameter at the arteriolar level but might also cause minor changes in diameter of the MCA, resulting in a slight systematic difference between relative changes in flow and flow velocity. A similar phenomenon previously had been described during hypothermic cardiopulmonary bypass. ${ }^{14}$

In conclusion, moderate hyperventilation, when compared with hypoventilation, increased net cerebral lactate efflux and decreased LOI and LGI in cardiovascular patients undergoing fentanyl-midazolam anesthesia. These metabolic changes suggest that the observed decrease in $\mathrm{CBF}, \mathrm{cDO}_{2}$, 
and $\mathrm{PjvO}_{2}$ may partly impair cerebral aerobic metabolism at clinically relevant levels of hypocapnia.

\section{Acknowledgments}

The authors gratefully thank Gerhard H. Visser, M.D., Ph.D. (Heemstede, The Netherlands), for his helpful comments on the interpretation of data, and Sanne Hoeks, Ph.D., Erasmus MC (Rotterdam, The Netherlands), for her expert advice in statistical analysis.

Support was provided solely from institutional and/or departmental sources.

\section{Competing Interests}

The authors declare no competing interests.

\section{Correspondence}

Address correspondence to Dr. Grüne: Erasmus MC, Department of Anesthesiology, Room H1283, PO Box 2040, 3000 CA Rotterdam, The Netherlands. f.grune@erasmusmc.nl. Information on purchasing reprints may be found at www.anesthesiology.org or on the masthead page at the beginning of this issue. Anesthesiology's articles are made freely accessible to all readers, for personal use only, 6 months from the cover date of the issue.

\section{References}

1. Brian JE Jr: Carbon dioxide and the cerebral circulation. ANESTHESIOLOGy 1998; 88:1365-86

2. Wax DB, Lin HM, Hossain S, Porter SB: Intraoperative carbon dioxide management and outcomes. Eur J Anaesthesiol 2010; 27:819-23

3. Nagata K, Buchan RJ, Yokoyama E, Kondoh Y, Sato M, Terashi H, Satoh Y, Watahiki Y, Senova M, Hirata Y, Hatazawa $\mathrm{J}$ : Misery perfusion with preserved vascular reactivity in Alzheimer's disease. Ann N Y Acad Sci 1997; 826:272-81

4. Meyer JS, Sawada T, Kitamura A, Toyoda M: Cerebral oxygen, glucose, lactate, and pyruvate metabolism in stroke. Therapeutic considerations. Circulation 1968; 37:1036-48

5. Robertson CS, Narayan RK, Gokaslan ZL, Pahwa R, Grossman RG, Caram P Jr, Allen E: Cerebral arteriovenous oxygen difference as an estimate of cerebral blood flow in comatose patients. J Neurosurg 1989; 70:222-30

6. Thees C, Scholz M, Schaller M D C, Gass A, Pavlidis C Weyland A, Hoeft A: Relationship between intracranial pressure and critical closing pressure in patients with neurotrauma. ANESTHESIOLOGY 2002; 96:595-9

7. Coles JP, Minhas PS, Fryer TD, Smielewski P, Aigbirihio F, Donovan T, Downey SP, Williams G, Chatfield D, Matthews JC, Gupta AK, Carpenter TA, Clark JC, Pickard JD, Menon DK: Effect of hyperventilation on cerebral blood flow in traumatic head injury: Clinical relevance and monitoring correlates. Crit Care Med 2002; 30:1950-9

8. Møller K, Strauss GI, Thomsen G, Larsen FS, Holm S, Sperling BK, Skinhøj P, Knudsen GM: Cerebral blood flow, oxidative metabolism and cerebrovascular carbon dioxide reactivity in patients with acute bacterial meningitis. Acta Anaesthesiol Scand 2002; 46:567-78

9. Clausen T, Scharf A, Menzel M, Soukup J, Holz C, Rieger A, Hanisch F, Brath E, Nemeth N, Miko I, Vajkoczy P, Radke J, Henze D: Influence of moderate and profound hyperventilation on cerebral blood flow, oxygenation and metabolism. Brain Res 2004; 1019:113-23

10. van Rijen PC, Luyten PR, van der Sprenkel JW, Kraaier V, van Huffelen AC, Tulleken CA, den Hollander JA: $1 \mathrm{H}$ and 31P NMR measurement of cerebral lactate, high-energy phosphate levels, and $\mathrm{pH}$ in humans during voluntary hyperventilation: Associated EEG, capnographic, and Doppler findings. Magn Reson Med 1989; 10:182-93

11. Friedman SD, Jensen JE, Frederick BB, Artru AA, Renshaw PF, Dager SR: Brain changes to hypocapnia using rapidly interleaved phosphorus-proton magnetic resonance spectroscopy at 4 T. J Cereb Blood Flow Metab 2007; 27:646-53

12. Stephan $\mathrm{H}$, Sonntag $\mathrm{H}$, Lange $\mathrm{H}$, Rieke $\mathrm{H}$ : Cerebral effects of anaesthesia and hypothermia. Anaesthesia 1989; 44:310-6

13. Stephan H, Gröger P, Weyland A, Hoeft A, Sonntag H: [The effect of sufentanil on cerebral blood flow, cerebral metabolism and the $\mathrm{CO}^{2}$ reactivity of the cerebral vessels in man]. Anaesthesist 1991; 40:153-60

14. Weyland A, Stephan H, Kazmaier S, Weyland W, Schorn B, Grüne DF, Sonntag H: Flow velocity measurements as an index of cerebral blood flow. Anesthesiology 1994; 81:1401-10

15. Cohen PJ, Wollman H, Alexander SC, Chase PE, Behar MG: Cerebral carbohydrate metabolism in man during halothane anesthesia: Effects of $\mathrm{PaCO}_{2}$ on some aspects of carbohydrate utilization. ANESTHESIOLOGY 1964; 25:185-91

16. Alexander SC, Smith TC, Strobel G, Stephen GW, Wollman H: Cerebral carbohydrate metabolism of man during respiratory and etabolic alkalosis. J Appl Physiol 1968; 24:66-72

17. Mielck F, Stephan H, Buhre W, Weyland A, Sonntag H: Effects of 1 MAC desflurane on cerebral metabolism, blood flow and carbon dioxide reactivity in humans. Br J Anaesth 1998; $81: 155-60$

18. Mielck F, Stephan H, Weyland A, Sonntag H: Effects of one minimum alveolar anesthetic concentration sevoflurane on cerebral metabolism, blood flow, and $\mathrm{CO}_{2}$ reactivity in cardiac patients. Anesth Analg 1999; 89:364-9

19. Rau G: [Measurement of the coronary blood flow with argonforeign gas method in the patient]. Basic Res Cardiol 1969; 58:322-98

20. Ohta Y, Ar A, Farhi LE: Solubility and partition coefficients for gases in rabbit brain and blood. J Appl Physiol 1979; 46:1169-70

21. Weyland A, Stephan H, Grüne F, Weyland W, Sonntag H: Effect of ketanserin on global cerebral blood flow and middle cerebral artery flow velocity. Anesth Analg 1995; 80:64-70

22. Weyland A, Buhre W, Grund S, Ludwig H, Kazmaier S, Weyland W, Sonntag H: Cerebrovascular tone rather than intracranial pressure determines the effective downstream pressure of the cerebral circulation in the absence of intracranial hypertension. J Neurosurg Anesthesiol 2000; $12: 210-6$

23. Widder B: Transkranielle Doppler-Sonographie bei zerebrovaskulären Erkrankungen, 1st edition. Berlin Heidelberg, Springer-Verlag, 1987

24. Halsey JH: Effect of emitted power on waveform intensity in transcranial Doppler. Stroke 1990; 21:1573-8

25. Dewey RC, Pieper HP, Hunt WE: Experimental cerebral hemodynamics. Vasomotor tone, critical closing pressure, and vascular bed resistance. J Neurosurg 1974; 41:597-606

26. Strauss GI, Møller K, Holm S, Sperling B, Knudsen GM, Larsen FS: Transcranial Doppler sonography and internal jugular bulb saturation during hyperventilation in patients with fulminant hepatic failure. Liver Transpl 2001; 7:352-8

27. McKennia MC, Dienel GA, Sonnewald U: Energy metabolism of the brain, Basic Neurochemistry, 8th edition. Edited by Bradly ST, Siegel GJ, Albers RW, Price DL. Amsterdam, Elsevier, 2011, pp 200-34

28. Cummings P: Arguments for and against standardized mean differences (effect sizes). Arch Pediatr Adolesc Med 2011; 165:592-6

29. Faul F, Erdfelder E, Buchner A, Lang AG: Statistical power analyses using $\mathrm{G}^{*}$ Power 3.1: Tests for correlation and regression analyses. Behav Res Methods 2009; 41:1149-60 
30. MacMillan V, Siesjö BK: The influence of hypocapnia upon intracellular $\mathrm{pH}$ and upon some carbohydrate substrates, amino acids and organic phosphates in the brain. J Neurochem 1973; 21:1283-99

31. Weyne J, Demeester G, Leusen I: Effects of carbon dioxide, bicarbonate and $\mathrm{pH}$ on lactate and pyruvate in the brain of rats. Pflugers Arch 1970; 314:292-311

32. Druml W, Grimm G, Laggner AN, Lenz K, Schneeweiss B Lactic acid kinetics in respiratory alkalosis. Crit Care Med 1991; 19:1120-4

33. Hirsch H, Grote G, Schlosser V: [On the effects of hexobarbituric acid on oxygen consumption and vulnerability of the brain]. Pflugers Arch Gesamte Physiol Menschen Tiere 1961; $272: 247-53$

34. Granholm L: Cerebral effects of hyperventilation. Acta Anaesthesiol Scand Suppl 1971; 45:114-22

35. Grote J, Zimmer $\mathrm{K}$, Schubert R: Effects of severe arterial hypocapnia on regional blood flow regulation, tissue $\mathrm{PO}$ and metabolism in the brain cortex of cats. Pflugers Arch 1981; 391:195-9

36. Kennealy JA, McLennan JE, Loudon RG, McLaurin RL: Hyperventilation-induced cerebral hypoxia. Am Rev Respir Dis 1980; 122:407-12

37. Duong TQ, Iadecola C, Kim SG: Effect of hyperoxia, hypercapnia, and hypoxia on cerebral interstitial oxygen tension and cerebral blood flow. Magn Reson Med 2001; 45:61-70

38. van Hall G, Strømstad M, Rasmussen P, Jans O, Zaar M, Gam C, Quistorff B, Secher NH, Nielsen HB: Blood lactate is an important energy source for the human brain. J Cereb Blood Flow Metab 2009; 29:1121-9

39. Figley CR: Lactate transport and metabolism in the human brain: Implications for the astrocyte-neuron lactate shuttle hypothesis. J Neurosci 2011; 31:4768-70

40. Seifert T, Secher NH: Sympathetic influence on cerebral blood flow and metabolism during exercise in humans. Prog Neurobiol 2011; 95:406-26

41. Gibbs EL, Lennox WG, Nims LF, Gibbs FA: Arterial and cerebral venous blood: Arterial-venous differences in man. J Biol Chem 1942; 144:325-32

42. Gam CM, Rasmussen P, Secher NH, Seifert T, Larsen FS, Nielsen HB: Maintained cerebral metabolic ratio during exercise in patients with beta-adrenergic blockade. Clin Physiol Funct Imaging 2009; 29:420-6

43. Hyder F, Shulman RG, Rothman DL: A model for the regulation of cerebral oxygen delivery. J Appl Physiol 1998; 85:554-64

44. Hyder F, Kennan RP, Kida I, Mason GF, Behar KL, Rothman D: Dependence of oxygen delivery on blood flow in rat brain: A 7 tesla nuclear magnetic resonance study. J Cereb Blood Flow Metab 2000; 20:485-98

45. Jones MD Jr, Traystman RJ, Simmons MA, Molteni RA: Effects of changes in arterial $\mathrm{O}_{2}$ content on cerebral blood flow in the lamb. Am J Physiol 1981; 240:H209-15

46. Michenfelder JD, Sundt TM, Fode N, Sharbrough FW: Isoflurane when compared to enflurane and halothane decreases the frequency of cerebral ischemia during carotid endarterectomy. ANESTHESIOLOGY 1987; 67:336-40

47. Wolff CB: Normal cardiac output, oxygen delivery and oxygen extraction. Adv Exp Med Biol 2007; 599:169-82
48. Hutchinson PJ, Gupta AK, Fryer TF, Al-Rawi PG, Chatfield DA, Coles JP, O'Connell MT, Kett-White R, Minhas PS, Aigbirhio FI, Clark JC, Kirkpatrick PJ, Menon DK, Pickard JD: Correlation between cerebral blood flow, substrate delivery, and metabolism in head injury: A combined microdialysis and triple oxygen positron emission tomography study. J Cereb Blood Flow Metab 2002; 22: 735-45

49. Mik EG, Johannes T, Zuurbier CJ, Heinen A, Houben-Weerts JH, Balestra GM, Stap J, Beek JF, Ince C: In vivo mitochondrial oxygen tension measured by a delayed fluorescence lifetime technique. Biophys J 2008; 95:3977-90

50. Wilson DF: Quantifying the role of oxygen pressure in tissue function. Am J Physiol Heart Circ Physiol 2008; 294:H11-3

51. Mik EG: Hyperbaric oxygen preconditioning: What remains between hypoxia and hyperoxia? Clin Exp Pharmacol Physiol 2011; 38:656-7

52. Alberti E, Hoyer S, Hamer J, Stoeckel H, Packschiess P, Weinhardt $\mathrm{F}$ : The effect of carbon dioxide on cerebral blood flow and cerebral metabolism in dogs. Br J Anaesth 1975; 47:941-7

53. Mielck F, Wietasch G, Weyland A, Buhre W, Meier-Theile C, Hoeft A, Sonntag H: Reliability of cerebral blood flow measurements by transcerebral double-indicator dilution technique. Eur J Anaesthesiol 2001; 18:653-61

54. Albrecht RF, Miletich DJ, Ruttle M: Cerebral effects of extended hyperventilation in unanesthetized goats. Stroke $1987 ; 18: 649-55$

55. Wietasch GJ, Mielck F, Scholz M, von Spiegel T, Stephan $\mathrm{H}$, Hoeft A: Bedside assessment of cerebral blood flow by double-indicator dilution technique. AnESTHESIOLOGY 2000; 92:367-75

56. Baughman VL, Hoffman WE, Albrecht RF, Miletich DJ: Cerebral vascular and metabolic effects of fentanyl and midazolam in young and aged rats. Anesthesiology 1987; 67:314-9

57. Hancock SM, Mahajan RP, Athanassiou L: Noninvasive estimation of cerebral perfusion pressure and zero flow pressure in healthy volunteers: The effects of changes in end-tidal carbon dioxide. Anesth Analg 2003; 96:847-51

58. McCulloch TJ, Turner MJ: The effects of hypocapnia and the cerebral autoregulatory response on cerebrovascular resistance and apparent zero flow pressure during isoflurane anesthesia. Anesth Analg 2009; 108:1284-90

59. Tauchert M, Kochsiek K, Heiss HW, Rau G, Bretschneider HJ: [Methods of measuring the blood supply of an organ using argon]. Z Kreislaufforsch 1971; 60:871-80

60. Lassen NA: Normal average value of cerebral blood flow in younger adults is $50 \mathrm{ml} / 100 \mathrm{~g} / \mathrm{min}$. J Cereb Blood Flow Metab 1985; 5:347-9

61. Madsen PL, Sperling BK, Warming T, Schmidt JF, Secher NH, Wildschiødtz G, Holm S, Lassen NA: Middle cerebral artery blood velocity and cerebral blood flow and $\mathrm{O}_{2}$ uptake during dynamic exercise. J Appl Physiol 1993; 74:245-50

62. Nuttall GA, Cook DJ, Fulgham JR, Oliver WC Jr, Proper JA: The relationship between cerebral blood flow and transcranial Doppler blood flow velocity during hypothermic cardiopulmonary bypass in adults. Anesth Analg 1996; $82: 1146-51$ 